\title{
FAKTOR PERAWAT TERHADAP KEJADIAN MEDICATION ADMINISTRATION ERROR DI INSTALASI RAWAT INAP
}

\author{
NURSE FACTORS TO THE OCCURANCE OF MEDICATION ADMINISTRATION ERROR IN INPATIENT \\ WARD
}

Vidia Sabrina Budihardjo

Ikatan Ahli Kesehatan Masyarakat Indonesia (IAKMI) Provinsi Jawa Timur

E-mail:vidiasabrina@gmail.com

\begin{abstract}
Medication administration error is one of medication error that happened due to unfulfillment of drug instruction or drug administration that is different with the recipe. From the initial survey conducted in 2015, there were 13 events medication errors known in 2014-2015 in RSU Haji Surabaya. Based on Kepmenkes RI nomor 129/Menkes/SK/II/2008 about Minimum Service Standards, medication incident should not be any error occurred in the Hospital.This study was an observational descriptive study aimed to identify factors that contribute to the incidence of medication errors. Respondents were 56 nurses that worked on 7 inpatient wards. Variablesi $n$ this research are: the skills of nurses, nurse's knowledge, and communication between nurse and patients. The result showed that the incidence of medication error in 2014-2016 amounted to 14 events that occurred in most of the inpatient ward (57.1\%). Most of inpatient ward $(57.41 \%)$ had good skill of nurses, most of the inpatient wards $(57.1 \%)$ had a sufficient knowledge and communication of nurses. From this study it can be concluded that the skills of nurses, nurse's knowledge, communication between nurse and patients are contributing to the incidence of medication errors in RSU Haji Surabaya.
\end{abstract}

Keywords: inpatient ward, medication errors, nurses,

\section{PENDAHULUAN}

Medication error adalah kejadian yang merugikan pasien akibat pemakaian obat, tindakan, dan perawatan selama dalam penanganan tenaga kesehatan yang sebetulnya dapat dicegah (Depkes RI, 2004). Bentuk-bentuk medication error yang terjadi dapat berupa : unordered error, extra dose error, omission error, wrong dose error, wrong route error, wrong time error dan wrong dosage form error (Depkes RI, 2008).

Medication error adalah jenis Medical Error yang paling umum terjadi di berbagai rumah sakit. Diperkirakan 7000 orang meninggal pertahun akibat medication error (Kinninger, 2003). Studi lain yang dilakukan di 36 rumah sakit di Amerika pada tahun 2002, ditemukan bahwa probabilitas kejadian medication error sebesar 2 kejadian setiap harinya. Sementara itu, Studi yang dilakukan di RSUD Anwar Makkatutu Bantaeng melaporkan bahwa sebanyak 18 kasus medication error terjadi ditahun 2010, 16 kasus ditahun 2011 dan naik hingga 21 kasus di tahun 2012. Hal tersebut menunjukkan bahwa kasus medication error masih sering terjadi dalam pelayanan kesehatan di Indonesia. Berdasarkan Kepmenkes RI nomor 129/Menkes/SK/II/2008 tentang Standar Pelayanan Minimal, tidak adanya kejadian kesalahan pemberian obat sebesar $100 \%$, hal itu berarti bahwa seharusnya kejadian kesalahan obat atau medication error tidak boleh terjadi satupun dalam pelayanan kesehatan.

Kasus medication error pun masih ditemui di RSU Haji Surabaya. Dari Instalasi yang terpapar kejadian medication error yaitu : ICU, ICCU, Kamar Bersalin, IGD dan rawat inap, kejadian medication error paling banyak ditemukan di instalasi rawat inap. Sebanyak 13 kejadian medication error ditemukan di Intalasi rawat Inap RSU Haji Surabaya 
pada tahun 2014-2015. Sebanyak 7 kejadian pada tahun 2014 dan 6 kejadian pada tahun 2015.

Medication error dapat terjadi disetiap tahapan pengobatan. Menurut National Patient Safety Agency (2004), medication error pada tahap administration error adalah jenis kesalahan yang paling sering terjadi dan menimbulkan dampak yang paling parah dibandingkan jenis kesalahan lainnya. Pihak yang paling bertanggung jawab dalam tahap drug administration adalah perawat, sebab perawat berkewajiban dalam tindakan pemberian obat. Faktor Individu perawat, seperti : rendahnya pengetahuan tentang farmakologi, miskomunikasi, kelelahan, salah membaca label obat, dan ketidak patuhan dalam melaksanakan prinsip benar pemberian obat merupakan faktor yang dapat menyebabkan medication administration error (Savvato, 2014).

Berdasarkan data tersebut diatas, masalah penelitian yang ditemukan adalah adanya kejadian medication errror di Instalasi Rawat Inap RSU Haji Surabaya sebesar 13 kejadian pada tahun 20142015. Dengan demikian, penelitian ini bertujuan untuk menggambarkan faktor perawat yang berkontribusi terhadap kejadian medication error di Instalasi Rawat Inap RSU Haji Surabaya.

\section{PUSTAKA}

\section{Medication error}

Medication error merupakan masalah yang sering terjadi pada pasien rawat inap. Secara umum Medication error didefinisikan sebagai peresepan, pemberian dan administrasi obat yang salah, yang menyebabkan konsekuensi tertentu.
Medication erroradalah suatu kesalahan dalam proses pengobatan yang masih berada dalam pengawasan dan tanggung jawab profesi kesehatan, pasien atau konsumen, dan seharusnya dapat dicegah (Cohen, 1999).

Medication error dibedakan menjadi 3 jenis berdasarkan tahap pengobatan, yaitu : prescribing error (resep tidak terbaca, data pasien tdak lengkap, nama obat yang tidak jelas), dispensing error (bentuk sediaan yang tidak tepat, obat kadaluarsa, instruksi obat yang tidak tepat), dan administration error (kesalahan waktu pemberian obat, dosis tidak tepat, teknik atau rute pemberian obat yang salah).

Seperti yang telah dipaparkan diatas, medication administration error adalah salah satu jenis medication error yang disebabkan karena tidak terpenuhinya instruksi pemberian obat atau pemberian obat yang tidak sesuai dengan resep (Maralyn, 2005). Medication admnistration error merupakan jenis medication error yang paling banyak terjadi. Dalam medication error, sebanyak $60 \%$ diantaranya adalah kasus administration error (Hughes, 2008). Medication administration error dapat menjadi salah satu penyebab Adverse Drug Events (ADE) atau efek samping yang tidak diinginkan dalam pengobatan. Medication administration error dilaporkan sebagai salah satu penyebab tingginya angka morbiditas dan mortalitas pada pasien rawat inap (Tissot et al 2003; Baker et al 2002).

Medication error dapat menyebabkan efek samping yang membahayakan yang potensial memicu resiko fatal dari penyakit. Suatu sistem 
praktik pengobatan yang aman perlu dikembangkan dan dipelihara untuk memastikan bahwa pasien menerima pelayanan dan proteksi sebaik mungkin. Hal ini dikarenakan semakin bervariasinya obatobatan dan meningkatnya jumlah dan jenis obat yang ditulis per pasien saat ini.

\section{Pengetahuan Perawat}

Pengetahuan adalah dasar bagi seseorang untuk melakukan pekerjaan. Begitupun perawat, dituntut untuk memiliki pengetahuan keperawatan yang baik untuk dapat memberikan pelayanan yang berkualitas.

Menurut Notoatmojo (2011) Pengetahuan merupakan hasil dari "tahu" yang terjadi setelah orang mengadakan penginderaan terhadap suatu objek tertentu terutama melalui mata dan telinga. Bila seseorang dapat menjawab pertanyaan pertanyaan mengenai suatu bidang tertentu dengan lancar, baik secara lisan maupun tertulis maka dapat dikatakan mengetahui bidang tersebut.

Pengetahuan perawat yang dimaksud dalam penelitian adalah pengetahuan mengenai pemberian obat dan pengetahuan mengenai medication error. Berdasarkan penelitian yang dilakukan di Iran pada tahun 2013 mengenai medication error, ditemukan bahwa salah satu faktor penyebab kejadian medcation error merupakan kurangnya pengetahuan perawat dibidang farmakologi.

Dengan meningkatnya jumlah obat yang tersedia di rumah sakit dan masyarakat maka perawat bertanggungjawab untuk memperbaharui pengetahuan mereka tentang obat-obatan (O'Shea,
1999).Pendidikan yang berkesinambungan bagi tenaga kesehatan sangat diperlukan, terlebih lagi pada obat-obatan yang dianggap baru di suatu pelayanan kesehatan tersebut. Kebijakan terkait obat-obatan, prosedur, berbagai informasi, dan medication error harus tersedia bagi tenaga kesehatan (Anderson, 2010).

\section{Keterampilan Perawat}

Dalam praktik keperawatan mutlak diperlukan skill atau keterampilan yang baik agar dapat memberikan pelayanan yang berkualitas. Menurut Gordon (1999) pengertian keterampilan adalah kemampuan untuk mengoperasikan pekerjaan secara mudah dan cermat. Pengertian ini biasanya cenderung pada aktivitas psikomotor. Sedangkan, menurut Nadler (2000) pengertian keterampilan (skill) adalah kegiatan yang memerlukan praktek atau dapat diartikan sebagai implikasi dari aktivitas.

Salah satu keterampilan yang harus dimiliki oleh perawat adalah keterampilan dalam memberikan obat. Dalam melakukan pemberian obat seorang perawat dituntut untuk menerapkan prinsip 12 benar pemberian obat. Berikut ini merupakan rincian prinsip 12 benar pemberian obat : benar klien, benar obat, benar dosis, benar waktu. benar rute pemberian, benar informasi medikasi kepada pasien, benar dokumentasi, hak klien untuk menolak, benar pengkajian, benar evaluasi, benar reaksi terhadap makanan, dan benar reaksi dengan obat lain.

Tindakan keperawatan profesional mempunyai peranan yang penting dalam 
pelaksanaan pemberian obat. Untuk dapat memberikan obat secara benar dan efektif, perawat harus mengetahui tentang indikasi, dosis, dan cara pemberian obat dan efek samping yang mungkin terjadi dari setiap obat yang diberikan (Priharjo, 2008).

\section{Komunikasi Perawat}

Dalam pelayanan kesehatan, komunikasi adalah sebuah kegiatan yang lazim terjadi antara seorang perawat dengan pasien. Menurut Hoveland dalam Widjaja, (2000) komunikasi adalah suatu proses dimana seorang individu menyampaikan perangsang (biasanya lambang-lambang dalam bentuk kata-kata) untuk mengubah tingkah laku orang lain/individu lain. Untuk itu harus ada kesepahaman arti dalam proses penyampaian informasi tersebut agar tercapai komunikasi yang efektif.

Komunikasi antara perawat dengan pasien harus disampaikan secara jelas agar pasien memahami keadaan kesehatannya ataupun instruksi mengenai pengobatan yang disampaikan oleh perawat. Hal-hal yang harus diinformasikan dan didiskusikan pada pasien adalah :Pemahaman yang jelas mengenai indikasi penggunaan obat, Peringatan yang berkaitan dengan proses pengobatan, informasi mengenai efek samping obat, Reaksi obat yang tidak diinginkan (Adverse Drug Reaction - ADR) dan informasi mengenai penyimpanan dan penanganan obat di rumah termasuk mengenali obat yang sudah rusak atau kadaluarsa (Depkes RI, 2008).

\section{METODE}

Penelitian ini merupakan jenis penelitian deskriptif observasional, dimana dalam pelaksanaannya tidak memberikan perlakuan kepada obyek atau lokasi penelitian. Penelitian ini bertujuan untuk mengidentifikasi dan menggambarkan faktor-faktor yang berkontribusi terhadap kejadian medication error. Pendekatan yang digunakan dalam pengambilan data adalah cross sectional.

Penelitian ini dilaksanakan di Instalasi Rawat Inap RSU Haji Surabaya, yang melibatkan 7 ruangan rawat inap yaitu : shofa 2 , shofa 3 , shofa 4 , marwah 1, marwah 2, marwah 3, dan marwah 4 . Populasi penelitian adalah perawat yang secara langsung berinteraksi dengan pasien. Jumlah populasi dalam penelitian ini sebesar 132 perawat yang terbagi di 7 ruangan rawat inap. Pengambilan sampel dilakukan menggunakan teknik cluster sampling. Berdasarkan perhitungan menggunakan teknik cluster sampling maka sampel penelitian pada masing-masing ruangan sebesar 8 perawat, sehingga total keseluruhan responden adalah 56 perawat.

Unit analisis dalam penelitian ini adalah 7 ruangan rawat inap, sehingga hasil penelitian akan disimpulkan berdasarkan masing-masing ruangan. Variabel bebas (independent)dalam penelitian ini adalah pengetahuan perawat, keterampilan perawat, dan komunikasi perawat, sedangkan variabel terikat (dependent) adalah kejadian medication error di Instalasi Rawat Inap RSU Haji 
Surabaya pada tahun 2014-2016. Kedua variabel yang diteliti akan disajikan dalam tabel distribusi frekuensi, kemudian hasil akan diinterpretasikan untuk memaparkan faktor-faktor yang berkontribusi terhadap kejadian medication error.

\section{HASIL DAN PEMBAHASAN}

Hasil penelitian yang menjelaskan karakteristik responden dapat dilihat pada tabel 1 . Dapat diketahui bahwa sebagian besar responden $(75,0 \%)$ berada pada usia 18-40 tahun atau merupakan usia dalam rentang dewasa dini menurut teori Hurlock (2002). Begitupun dengan pendidikan para responden, dapat diketahui bahwa sebagian besar responden $(75,0 \%)$ berpendidikan D3 dan sebagian kecil reponden (25,0\%) berpendidikan S1. Maka, seluruh responden telah memenuhi persyaratan yang ditetapkan dalam PERMENKES No 148 tahun 2010 tentang izin dan penyelenggaraan praktek perawat yang menyatakan bahwa, seorang perawat dapat melakukan praktek keperawatan setelah mendapakan Surat ljin Praketk Perawat (SIPP) dan minimal berpendidikan D3 keperawatan. Sedangkan untuk lama bekerja, dapat diketahui bahwa hampir setengah responden $(44,6 \%)$ telah bekerja selama lebih dari 5 tahun.

\section{Pengetahuan Perawat}

Pengetahuan yang dimaksud dalam penelitian ini adalah pengetahuan perawat mengenai medication error dan pemberian obat. Aspek pengetahuan yang dikaji antara lain : Definisi medication error, Pencegahan medication error, Akibat yang ditimbulkan karena medication error, Pengkajian yang dilakukan dalam pemberian obat,Prinsip benar pemberian obat, Rute pemberian obat dan beberapa pertanyan lain seputar pemberian obat dan medication error.

Tabel1.Distribusi Frekwensi Karakteristik Perawat Di Instalasi Rawat Inap RSU Haji Surabaya Tahun 2016

\begin{tabular}{crr}
\hline Karakterisitik & Jumlah & Presentase (\%) \\
\hline Usia Perawat $18-40$ Tahun & 42 & 75,0 \\
41-60 Tahun & 14 & 25,0 \\
\hline Total & 56 & 100,0 \\
\hline Pendidikan Perawat & & \\
D III & 42 & 75,0 \\
S 1 & 14 & 25,0 \\
\hline Total & 56 & 100,0 \\
\hline Lama bekerja di Ruangan & 3 & 5,4 \\
1 Tahun & 17 & 30,4 \\
1-3 Tahun & 11 & 19,6 \\
$>$ 3 Tahun & 11 & 44,6 \\
\hline 5 Tahun & 25 & 100,0 \\
\hline Total & 56 &
\end{tabular}


Tabel 2. Distribusi Frekwensi Pengetahuan Perawat, Keterampilan Perawat, Dan Komunikasi Perawat Pada Pasien Di Instalasi Rawat Inap RSU Haji Surabaya Pada Tahun 2016.

\begin{tabular}{crr}
\hline Variabel & Jumlah & Persentase (\%) \\
\hline Pengetahuan Perawat & 3 & 42,9 \\
Baik & 4 & 57,1 \\
Kukup & 0 & 0 \\
\hline Kurang & 7 & 100,0 \\
\hline Kotal & 4 & 57,1 \\
Baik & 3 & 42,9 \\
Cukup & 3 & 0 \\
Kurang & 0 & 100,0 \\
\hline Total & 7 & 42,9 \\
Baik & & 57,1 \\
Cukup & 3 & 0,0 \\
\hline Kurang & 4 & 100,0 \\
\hline Total & 0 & 7 \\
\hline
\end{tabular}

Berdasarkan tabel 2 dapat diketahui bahwa sebagian besar ruangan $(57,1 \%)$ di Instalasi Rawat Inap RSU Haji Surabaya memiliki tingkat pengetahuan perawat yang cukup. Sedangkan hampir setengah ruangan lainnya (42,9\%) memiliki tingkat pengetahuan perawat yang baik. Pengetahuan perawat diperlukan sebagai dasar dari setiap tindakan keperawatan yang dilakukan. Dengan pengetahuan mengenai pemberian obat yang baik, maka seorang perawat dapat memberikan tindakan pemberian obat dengan tepat dan aman kepada pasien. Begitu juga dengan pengetahuan perawat mengenai medication error, semakin baik tingkat pengetahuan perawat maka ia akan lebih cepat mengidentifikasi sebuah kesalahan sebelum kesalahan itu mengenai pasien (Matsumoto 2008).

\section{Keterampilan Perawat}

Melakukan pemberian obat adalah tanggung jawab terbesar bagi perawat di Rumah Sakit, oleh karena itu perawat harus menggali dan memahami tentang keterampilan apa yang harus dikembangkan guna memberikan pelayanan yang baik (Matsumoto, 2008). Keterampilan yang dimaksud dalam penelitian ini adalah keterampilan perawat dalam pemberian obat. Aspek keterampilan perawat dikaji dengan menggunakan indikator 12 benar pemberian obat dan tindakan persiapan pra pemberian obat.

Dari hasil penelitian yang disajikan dalam tabel 2, dapat diketahui bahwa sebagian besar ruangan $(57,1 \%)$ memiliki tingkat keterampilan perawat yang baik, sementara hampir setengah ruangan lainnya $(42,9 \%)$ memiliki keterampilan perawat yang cukup.

\section{Komunikasi Perawat}

Komunikasi perawat yang dimaksud dalam penelitian ini adalah komunikasi perawat dengan pasien pada saat tindakan pemberian obat dilakukan. Komunikasi perawat kepada pasien menggambarkan bagaimana perawat tersebut memberikan informasi mengenai efek samping obat, jadwal pemberian obat, cara pemberian obat, memastikan pemahaman informasi, dan 
memberikan jawaban atas semua pertanyaan pasien seputar obat-obatan yang akan ia terima.

Dari hasil penelitian yang disajikan dalam tabel 2 dapat diketahui bahwa, komunikasi perawat dengan pasien di sebagian besar ruangan $(57,1 \%)$ memperoleh kategori cukup. Sedangkan hampir setengahnya (42,9\%) memperoleh kategori baik.

\section{Kejadian Medication error}

Medication error merupakan suatu kesalahan dalam pengobatan yang masih dalam tanggung jawab profesi tenaga kesehatan yang seharusnya dapat dicegah (Cohen, 1991). Berdasarkan Permenkes RI nomor 129/menkes/SK/II/2008 tentang Standar Pelayan Minimal, menyebutkan bahwa medication error tidak boleh terjadi satu pun dalam pelayanan kesehatan. Kejadian medication error dalam penelitian ini dikelompokkaan menjadi 2 kategori yaitu : terjadi dan tidak terjadi.

Berdasarkan tabel 3 dapat diktahui bahwa, Kejadian medication error terjadi di sebagian besar ruangan $(71,4 \%)$ di instalasi rawat inap RSU Haji Surabaya. Sedangkan sebagian kecil $(28,4 \%)$ merupakan ruangan yang tidak terdapat kejadian medication error. Jenis kesalahan yag terjadi antara lain, waktu pemberian obat yang tidak sesuai, salah membaca advice dokter, pemberian obat dengan dosis berlebih dan obat yang tertukar dengan pasien lain.

Medication error dapat menyebabkan efek samping yang membahayakan dan dapat memicu resiko fatal dari penyakit, sehingga secara tidak langsung medication error dapat menyebabkan kerugian bagi pasien berupa perpanjangan hari perawatan.

Tabel 3.Distribusi Frekwensi Kejadian Medication error di Instalasi Rawat Inap RSU Haji Surabaya Pada Tahun 2016

\begin{tabular}{crr}
\hline $\begin{array}{c}\text { Kejadian Medication } \\
\text { error }\end{array}$ & Jumlah & $\begin{array}{c}\text { Presentase } \\
(\%)\end{array}$ \\
\hline Tidak Terjadi & 2 & 28,6 \\
Terjadi & 5 & 71,4 \\
\hline Total & 7 & 100,0 \\
\hline
\end{tabular}

\section{Hubungan Pengetahuan Perawat Dengan Kejadian Medication error \\ ASHP guidelines on preventing medication}

errrs in hospital (2003) menyampaikan bahwa, kurangnya pengetahuan perawat merupakan salah satu faktor yang mempengaruhi medication error. Berdasarkan tabel 4 dapat diketahui bahwa sebagian besar $(66,7 \%)$ dari seluruh ruangan rawat inap dengan tingkat pengetahuan perawat yang baik, merupakan ruangan yang tidak terdapat kejadian medication error. Adapun ruangan dengan tingkat pengetahuan yang cukup, seluruhnya (100\%) merupakan ruangan yang terdapat kejadian medication error. Dari paparan hasil penelitian tersebut, dapat disimpulkan bahwa semakin baik tingkat pengetahuan perawat maka akan semakin kecil angka kejadia medication error di sebuah ruangan.

Hasil penelitian tersebut sejalan dengan penelitian yang dilakukan oleh Yunus (2013) yang menjelaskan bahwa ruang perawatan dengan pengetahuan perawat yang baik, angka kejadian kesalahan pengobatannya semakin kecil. Dalam penelitian tersebut juga menyimpulkan bahwa terdapat hubungan antara pengetahuan perawat dengan kesalahan pengobatan. Begitu juga dengan penelitian yang dilakukan oleh Amik (2014) yang menjelaskan bahwa perawat dengan pengetahuan 
yang baik lebih sedikit melakukan kesalahan dalam pengobatan, serta lebih bisa mengidentifikasi kesalahan pengobatan sebelum kesalahan tersebut mencapai pasien.
Menurut O'Shea (1999), perawat bertanggungjawab untuk mengelola obat-obatan sehingga mereka memerlukan pengetahuan mengenai efek samping dan dosis yang benar dari setiap obat yang mereka kelola

Tabel 4. Tabulasi Silang Antara Pengetahuan perawat, keterampilan perawat, dan komunikasi perawat dengan pasien dengan kejadian medication error di Instalasi Rawat Inap RSU Haji Surabaya pada tahun 2016

\begin{tabular}{|c|c|c|c|c|c|c|}
\hline \multirow{3}{*}{ Variabel } & \multicolumn{6}{|c|}{ Kejadian Medication error } \\
\hline & \multicolumn{2}{|c|}{ Terjadi } & \multicolumn{2}{|c|}{ Tidak terjadi } & \multirow[t]{2}{*}{ Jumlah } & \multirow{2}{*}{$\begin{array}{c}\text { Persentase } \\
(\%)\end{array}$} \\
\hline & $\mathbf{n}$ & (\%) & $\mathbf{n}$ & $(\%)$ & & \\
\hline \multicolumn{7}{|l|}{ Pengetahuan Perawat } \\
\hline Baik & & 66,7 & 1 & 33,3 & 3 & 100,0 \\
\hline Cukup & & 0,0 & 4 & 100,0 & 4 & 100,0 \\
\hline \multicolumn{7}{|l|}{ Keterampilan Perawat } \\
\hline Baik & & 50,0 & 2 & 50,0 & 4 & 100,0 \\
\hline Cukup & & 0,0 & 3 & 100,0 & 3 & 100,0 \\
\hline \multicolumn{7}{|c|}{$\begin{array}{l}\text { Komunikasi Perawat dengan } \\
\text { Pasien }\end{array}$} \\
\hline Baik & & 66,7 & 1 & 33,3 & 3 & 100,0 \\
\hline Cukup & & 0,0 & 4 & 100,0 & 4 & 100,0 \\
\hline
\end{tabular}

\section{Hubungan Keterampilan Perawat Dengan} Kejadian Medication error

Seorang perawat adalah penghubung utama antara pasien dan obat yang akan masuk ketubuh pasien, hal ini berarti bahwa perawat tidak hanya memiliki keterampilan dalam memberikan obat sesuai dengan kebutuhan pasien, melainkan juga bertanggung jawab untuk menangkap kesalahan dalam perintah sebelum memberikan obat (Matsumoto, 2008).

Berdasarkan tabel 4 dapat diketahui bahwa, sebagian (50\%) ruangan dengan tingkat keterampilan perawat yang baik, merupakan ruangan yang terdapat kejadian medication error, dan sebagian lainnya (50\%) merupakan ruangan yang tidak terdapat kejadian medication error. Adapun ruangan dengan tingkat keterampilan perawat yang cukup, seluruhnya (100\%) merupakan ruangan yang terdapat kejadian medcation error. Dalam penelitian ini, kejadian medication error terjadi di ruangan dengan tingkat keterampilan perawat yang baik, maupun tingkat keterampilan perawat yang cukup. Namun, angka kejadian medication error di ruangan dengan tigkat keterampilan perawat yang cukup lebih tinggi daripada ruangan dengan tingkat keterampilan perawat yang baik.

Hasil penelitian tersebut sejalan dengan penelitian yang dilakukan oleh Ahmad (2013) yang menjelaskan bahwa ruang perawatan dengan keterampilan perawat dalam pemberian obat yang baik, angka kesalahan pengobatannya semakin kecil. Begitu juga dengan peneltian yang dilakukan oleh Wahyuni (2015) yang menyatakan bahwa terdapat hubungan yang signifikan antara tindakan perawat dalam penerapan prinsip benar pemberian obat dengan kejadian KTD dalam pengobatan.

Keterampilan perawat dalam pemberian obat dengan memperhatikan prinsip benar obat, benar pasien, benar dosis, benar waktu pemberian, 
benar tehnik pemberian dan prinsip benar pemberian obat lainnya, memegang peranan yang penting dalam medication error. Jika salah satu dari prinsip tersebut salah dilakukan maka dapat berpotensi menimbulkan medication error dan merugikan pasien yang berakibat pada perpanjangan hari perawatan.

\section{Hubungan Komunikasi Perawat Dengan Kejadian Medication error}

Komunikasi yang efektif antara perawat dengan pasien merupakan kunci dari patient safety (WHO, 2008). Berdasarkan sebuah studi yang disampaikan dalam artikel WHO "learning form error" (2008), didapatkan bahwa lebih dari 60\% error yang terjadi disebabkan oleh kurangnya komunikasi.

Berdasarkan hasil penelitian yang disajikan dalam tabel 4 dapat diketahui bahwa sebagian besar ruangan $(66,7 \%)$ yang memperoleh kategori baik dalam komunikasi perawat, merupakan ruangan yang tidak terdapat kejadian medication error. Sementara itu, seluruh ruangan (100\%) yang memperoleh kategori cukup dalam komunikasi perawat, merupakan ruangan yang terdapat kejadian medication error. Dari paparan hasil penelitian tersebut, dapat disimpulkan bahwa semakin baik komunikasi perawat maka akan semakin kecil angka kejadian medication error di sebuah ruangan.

\section{ASHP Guidelines on Preventing} medication error in Hospital (2003) menyampaikan bahwa, kurangnya komunikasi antara perawat dengan pasien berpotensi menyebabkan kejadian medication error. Lebih lanjut dijelaskan bahwa, salah satu peran perawat dalam pencegahan medication error adalah perawat wajib untuk menginformasikan segala sesuatu yang berkaitan dengan diagnosa dan informasi seputar pengobatan pasien.

Seorang perawat dapat menciptakan suasana kemitraan yang baik dengan menyediakan cukup waktu untuk berdialog dan berkonsultasi dengan pasien. Dengan adanya pemahaman mengenai informasi obat yang diperoleh pasien dari perawat, maka pasien dapat berperan serta dalam upaya kesehatannya.

\section{SIMPULAN}

Berdasarkan hasil dan pembahasan dapat diketahui bahwa kejadian medication error terjadi di ruangan rawat inap di RSU Haji Surabaya. Ruangan rawat inap memiliki tingkat keterampilan perawat yang baik, namun memiliki tingkat pengetahuan perawat dan kemampuan komunikasi perawat yang cukup.

Saran diperuntukkan bagi pihak manajemen dan Diklat RSU Haji Surabaya untuk dapat memberikan sosialisasi atau edukasi di bidang pengetahuan dan keterampilan mengenai obata-obatan atau farmakologi maupun medication error guna meminimalisir angka kejadian medication error hingga 0 untuk dapat memenuhi Standar Pelayanan Minimal Rumah Sakit. Begitupula dapat diadakan pelatihan komunikasi efektif bagi para perawat guna memberikan pelayanan dengan kualitas terbaik. 


\section{DAFTAR PUSTAKA}

A.W. Widjaja. 2002. Komunikasi dan Hubungan Masyarakat. Jakarta : PT. Bumi Aksara

Ahmad, Y. Hubungan Pengetahuan Nursing ErrorPerawat Dengan Penerapan Prinsip Enam Benar Pemberian Injeksi Di Ruang Rawat Inap Bangsal Dewasa RSUD Muntilan Kabupaten Magelang. Jurnal keperawatan Vol 1 no 3, Februari 2013.

American Society of Health-System Phamacist, 2003, ASHP Guideline on PhamacistConducted Patient Education and Conducted Patient Education and Conseling, Am. J. Health-Syst. Pharm.

Amik, M. 2014. Faktor-faktor Penyebab Medication Error. Jurnal Keperawatan Vol 2 no 1, Juli 2014.

Anderson BP, 2010. Townsend T. Medication Errors : Don't Let Them Happen to You. American Nurse today.

Baker, $\mathrm{K}$, et al. 2002. Observation method of detecting medication errors. American Journal of Health-System Pharmacy. 59, Dec.

Cohen, M.R., 1999, Medication errors American Pharmaceutical Association, Washington, DC.

Gordon. 1999. Keterampilan, Teori Motivasi dan Pengukurannya. PT. Grapindo Persada. Jakarta.

Hughes, RG. 2008. Patient Safety and Quality : An Evience -Based Handbook for Nurses. Rockville. Agency for helathcare reaserh and quality.

Hurlock, E.B. 2002. Psikologi Perkembangan. 5th edition. Erlanga: Jakarta.
Kinninger T. 2003 Health Finance Manager. The business case for medication safety. Feb;57(2):46-51.

Maralyn, Foureur. 2005. Medication adminstration errors : understanding the issue.Scholar paper. Victoria University of Wellington.

Matsumoto, A. 2008. Clinical Skills Landmark Patient Medication Adminitration. Journal of Nursing Scholarship

Nadler. 2000. Keterampilan dan Jenisnya.PT. Grapindo Persada. Jakarta.

National Patient Safety Agency. $2004 . \quad$ Seven step to patient safety, the full reference guide2nd, London.

Notoatmodjo, S. 2011. Pendidikan dan Perilaku Kesehatan. Jakarta. Rhineka Cipta.

O'Shea E. 1999. Factors Contributing to Medication Errors : A Literature Review. J Clin Nurs.

Priharjo, R. 2008. Tehnik Dasar Pemberian Obat Bagi Perawat. Jakarta : EGC.

Savvato Karavasiladou. 2014. An inside lok into th factors contributing to medication errors in the clinical nursing practice. Health Science Journal vol. 8, issue 1.

Tissot, E. et al. 2003. Observational study of potential risk factors of medication administration errors Pharmacy World Science

Wahyuni, R. M .2015.. Perilaku Perawat Menerapkan Prinsip Enam Benar Pemberian Obat Mencegah Kejadian Tidak Diharapkan. Jurnal keperawatan Volume 2 no 2, Juli 2015.

WHO. 2008. Learning From Error. Switzerland. $\mathrm{WHO}$. 